\title{
Income Inequalities in Hepatitis B Vaccination and Willingness to Pay Among Women of Reproductive Age in Hanoi, Vietnam
}

\author{
Xuan Thi Thanh Le, ${ }^{a}$ Nguyen Thao Thi Nguyen, ${ }^{b}$ Huong Thi Le, ${ }^{a}$ Toan Thanh Thi Do, ${ }^{a}$ Thang Huu Nguyen, ${ }^{a}$

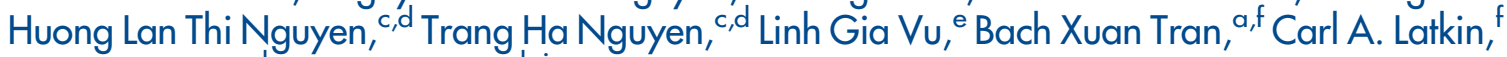 \\ Cyrus S.H. Ho, ${ }^{g, h}$ Roger C.M. Ho h,i
}

\section{Key Findings}

- Most women were willing to pay for the hepatitis B virus (HBV) vaccine and there was no difference in willingness to pay for HBV vaccination between income quintiles.

- The amount willing to pay for the vaccine was different between income levels for prices higher than US\$4.50.

\section{Key Implications}

- Because women from the lowest income quintile had the lowest awareness of the HBV vaccine, efforts on education and awareness of HBV and the vaccine should focus on low-income women.

- Given the high vertical transmission rates of HBV infection, policy makers should prioritize vaccinating women of reproductive age as well as newborns.

- In light of the finding that higher-income women were willing to pay more for the vaccine, adopting a sliding-scale payment system may mitigate challenges with funding and provide opportunities for equitable vaccine access.

\footnotetext{
a School for Preventive Medicine and Public Health, Hanoi Medical University, Hanoi, Vietnam.

b Duke University School of Medicine, Duke University, Durham, NC, USA.

cInstitute for Global Health Innovations, Duy Tan University, Da Nang, Vietnam.

dFaculty of Nursing, Duy Tan University, Da Nang, Vietnam.

${ }^{\text {e }}$ Center of Excellence in Evidence-based Medicine, Nguyen Tat Thanh University, Ho Chi Minh City, Vietnam.

fJohns Hopkins Bloomberg School of Public Health, Baltimore, MD, USA.

${ }^{9}$ Department of Psychological Medicine, National University Hospital,

Singapore, Singapore.

h Department of Psychological Medicine, Yong Loo Lin School of Medicine, National University of Singapore, Singapore, Singapore.

i Institute for Health Innovation and Technology (iHealthtech), National University of Singapore, Singapore, Singapore.

Correspondence to Huong Lan Thi Nguyen (nguyentlanhuong5@duytan.edu.vn).
}

\section{ABSTRACT}

Background: Hepatitis B virus (HBV) infection is endemic in Vietnam and can be transmitted from mother to child. Vaccination of women of reproductive age (WRA) can reduce this transmission. Because adult HBV vaccination in Vietnam follows a fee-for-service model, research is needed to determine the effect of household income on willingness to pay (WTP) to ensure equitable access to the vaccine.

Methods: A cross-sectional study was performed in Hanoi, Vietnam, in April 2018, among WRA. Questionnaires were administered to assess household income, HBV history, vaccination status, vaccine awareness, and WTP for the vaccine. Multivariable logistic and interval regression were performed to assess the impact of household income on WTP for HBV vaccine.

Results: This study found that $62.3 \%$ of all participants were willing to pay for the HBV vaccine with no differences in WTP across income quintiles. There were significant differences among household income levels in awareness of HBV vaccination and WTP amount beyond US $\$ 4.50$ with the lowest awareness and WTP amount among women from the lowest income quintiles.

Conclusions: Our data suggest the need to subsidize HBV vaccination for low-income women to ensure more equitable access to $\mathrm{HBV}$ vaccination. We propose that a sliding-scale payment method may be an effective strategy in light of limited funding to support vaccination expansion. An education campaign focusing on lower-income households should also be implemented in conjunction with this program. Further research would be required to evaluate consumer acceptance of this payment scheme and to develop an appropriate sliding scale to maximize vaccine uptake.

\section{INTRODUCTION}

$\mathbf{H}$ epatitis B virus (HBV) infection can cause both acute and chronic liver disease. In a small percentage of patients whose immune systems are unable to clear the virus, particularly children aged younger than 6 years old, HBV infection becomes chronic, often leading to cirrhosis and hepatocellular carcinoma. ${ }^{1}$ Though increasing availability of HBV vaccination has decreased morbidity and mortality, as of 2015, the World Health Organization (WHO) estimated that 257 million people worldwide are still living with chronic HBV infection with approximately 887,000 annual deaths due to cirrhosis or hepatocellular carcinoma. ${ }^{1}$ 
Vietnam has one of the highest rates of $\mathrm{HBV}$ infection in the world with $8.8 \%-19.0 \%$ of the general population estimated to be hepatitis $\mathrm{B}$ surface antigen-positive (HBsAg-positive). ${ }^{2-5}$ The disease is primarily vertically transmitted from mother to child during labor or less commonly, in-utero. ${ }^{6,7}$ If infants do not receive HBV immunoglobulin and vaccination at birth, mothers who are HBsAg-positive may transmit $\mathrm{HBV}$ infection at rates up to $90 \% .^{8}$ It is estimated that at least $50 \%$ of HBV-positive individuals acquired their infection perinatally or in early childhood. ${ }^{9}$ Horizontal transmission of $\mathrm{HBV}$ and disease incidence in adulthood is less clearly studied though data have suggested that extrafamilial horizontal transmission is likely high. ${ }^{10}$

Especially in endemic countries, HBV vaccination of neonates is an effective strategy to decrease transmission. ${ }^{11}$ In 2006, Vietnam began implementing widespread neonatal vaccination, resulting in a decrease in children who were HBsAg-positive from $3.62 \%$ to less than $2 \%$ between study periods 2000-2003 and 2008$2011 .{ }^{12}$ However, a national study in 2014 found that only $62.8 \%$ of children received the birth dose-far from universal coverage. ${ }^{12}$ As such, additional approaches should be considered to further decrease transmission rates.

A promising strategy that has been proposed to decrease rates of $\mathrm{HBV}$ infection transmission and improve disease control is vaccination of women of reproductive age (WRA). ${ }^{13}$ During pregnancy, women are vaccinated to confer immunity to neonates, ${ }^{14}$ given the risk of horizontal transmission in adulthood. However, there is a lack of randomized controlled trials on the efficacy of HBV vaccination for WRA to prevent maternal infection and consequently neonatal infection.

Currently, HBV vaccination among adults in

HBV vaccination among adults in Vietnam follows a fee-for-service model, which has worsened health disparities across socioeconomic statuses.
Vietnam follows a fee-for-service model, which has worsened health disparities across socioeconomic statuses. ${ }^{15}$ Indeed, in other countries that follow a similar model, including China and South Korea, income was found to be the largest contributor to inequalities in $\mathrm{HBV}$ vaccination. ${ }^{16,17}$ Studies examining the effect of income on HBV vaccination have not been conducted in Vietnam. This study aims to fill this gap by elucidating the role of household income on WRA's willingness to pay (WTP) and the amount they are willing to pay for $\mathrm{HBV}$ vaccination in an effort to pursue a more optimized payment scheme and equitable access across all income groups.

\section{METHODS}

\section{Study Design and Sample}

We performed a cross-sectional study in Dong Da (urban setting) and Ba Vi (rural setting) districts, Hanoi, Vietnam, in April 2018. In each district, we randomly selected 2 communes-Trung Tu and Phuong Lien communes in Dong Da district and Thuy An and Phong Van communes in Ba Vi district.

Women were invited to participate in this study if they were pregnant or had a child aged younger than 12 months. Other inclusion criteria were residence in the study setting for at least 6 months and willingness to participate in the study. Women were excluded if they had any cognitive impairment or disabilities that might affect their ability to understand and answer the questionnaire. A list of all eligible women in the study sites was compiled with the support of local health authorities. Then, participants were randomly selected using computer software and contacted via phone. If they refused to participate, we invited the next individual on the list. A total of 764 women were contacted to enroll in the study, and no one refused. However, data of only 695 women were included in the study because some participants did not report monthly household income (response rate $91.0 \%$ ).

\section{Ethics Approval}

The protocol of this study was reviewed and approved by the Ethics Committee of Hanoi Medical University (Code number:184/HMU-IRB; November 14, 2015). After hearing a one-on-one explanation of the study by trained health care workers at the Hanoi Medical University, all participants gave their verbal informed consent before participating in the study, acknowledging full understanding of the study's purpose, their rights to withdraw from the study at any time, and protection of confidentiality.

\section{Data Collection and Measurement}

Face-to-face interviews were conducted by medical students and health care workers at Hanoi Medical University in 2018. These data collectors were trained extensively regarding study purpose, communication, and interview skills. Moreover, they participated in piloting the structured questionnaire to ensure the consistency of the data collection process. Each interview lasted 2025 minutes. The questionnaire included questions regarding the following: 
FIGURE 1. Bidding Process Used During Interviews With Women of Reproductive Age to Determine Willingness to Pay for One Dose of Hepatitis B Vaccine, Hanoi, Vietnam

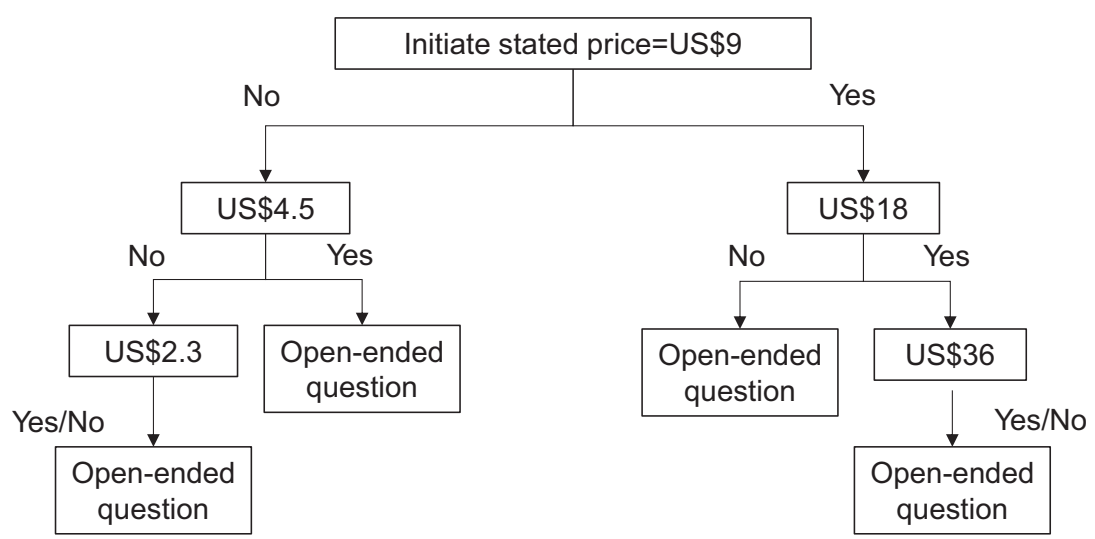

- Sociodemographic characteristics. We asked participants to report their age, education level, occupation, number of children, and residential setting (urban/rural). Household economic status was divided into 5 quintiles based on total household monthly income.

- HBV history, vaccination awareness, and uptake. We collected information on history of $\mathrm{HBV}$ infection, awareness of HBV vaccine, source of general vaccination knowledge, vaccination status against $\mathrm{HBV}$, and willingness to pay for $\mathrm{HBV}$ vaccines in the future.

- Willingness to pay for HBV vaccine. We applied a contingent valuation approach through double-bounded dichotomous choice to elicit WTP and the amount participants were willing to pay for 1 dose of HBV vaccine. The bidding process is illustrated in Figure 1. We first informed the women about the HBV vaccine and its effects on HBV prevention. Then, we asked them to state their willingness to pay for the vaccine. We used 200,000 VND (approximately US\$9) for a single vaccine as a first bid. This price was selected based on the actual price for the on-demand vaccination service. Initially, we asked participants about their WTP for the first bid. If they answered "no," they were asked whether they were willing to pay US $\$ 4.50$. If they had answered "yes," to the first bid, they were asked about their willingness to pay US $\$ 18$. At the end of the process, participants were asked the maximum amount they were willing to pay for 1 dose of the $\mathrm{HBV}$ vaccine.

\section{Statistical Analysis}

The data were analyzed by STATA version 14.0. Chi-squared and Kruska-Wallis tests were used to examine the difference in various characteristics among 5 household income quintiles. The differences in WTP by income quintile were explored by plotting the percentage of each quintile that was willing to pay a particular value or higher. As the value increases, the curves fall to reflect decreasing proportions of participants willing to pay higher prices. Lorenz curves and Gini coefficients were used to measure the extent of inequality based on the history of HBV vaccination and WTP for the HBV vaccine.

Multivariable logistic and interval regression were then performed to examine the factors associated with WTP and the maximum amount participants were willing to pay for 1 dose of HBV vaccine. These regression techniques were used along with stepwise forward selection strategies. A $P$-value $<.2$ was employed for variable selection. Statistical significance was determined if the $P$-value $<.05$.

\section{RESULTS}

Table 1 lists these findings with Q1 corresponding to the quintile with the lowest income and Q5 the highest income. Of 695 participants, the mean age and household monthly income were 27 years and US\$663.20, respectively. Household monthly income, residential setting (urban versus rural), and education level were significantly different between income quintiles $(P<.05)$. The lowest quintile had the largest percentage of rural residents, as well as the largest percentage of participants with high school and lower levels of education. 
TABLE 1. Sociodemographic Characteristics of Participants in Study of Effects of Household Income on Willingness to Pay for Hepatitis B Vaccine, Hanoi, Vietnam, ( $n=695)$

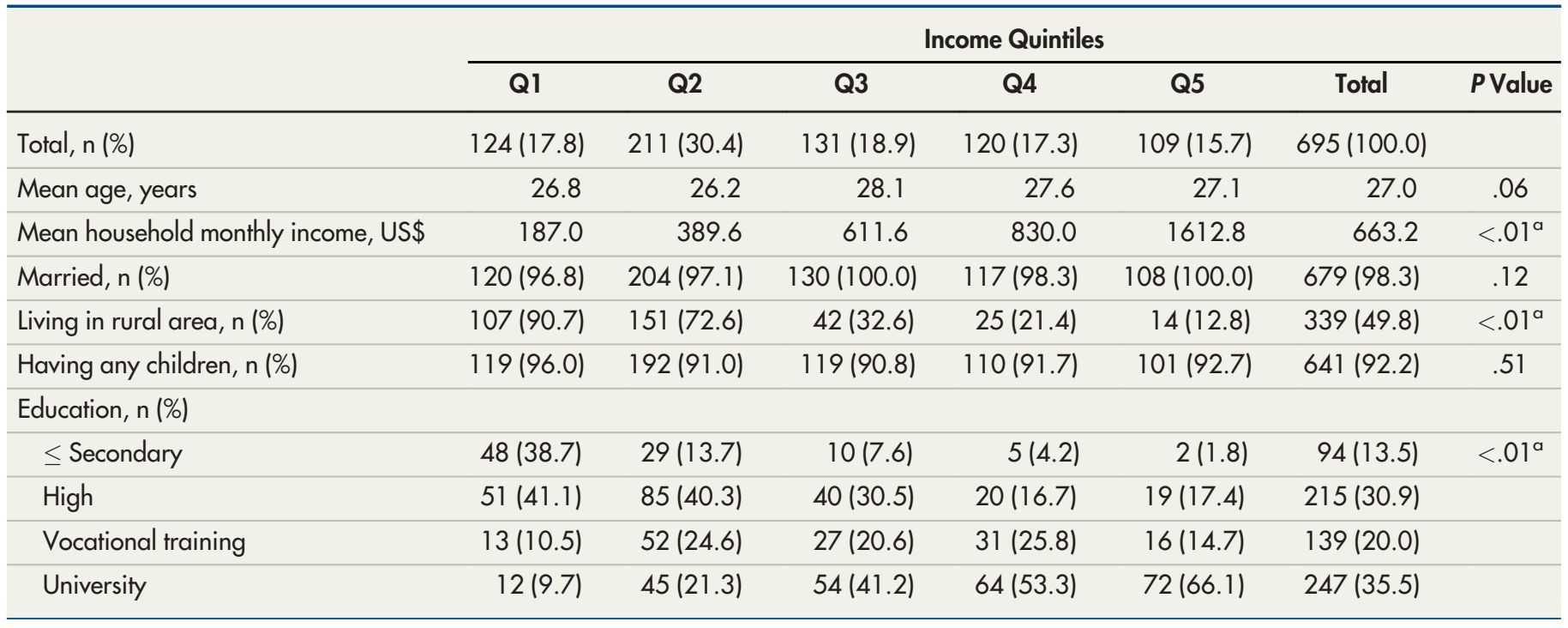

a Significant at $P<.05$. whe percentage of aware of the HBV vaccine was significantly different across quintiles.
Table 2 shows that $3.2 \%$ of participants had a history of HBV infection. The percentage of women who were aware of the HBV vaccine was significantly different across quintiles with the lowest rates in Q1 $(86.3 \%)$ and the highest in Q5 $(98.2 \%) \quad(P<0.5)$. Moreover, the percentage of women who had previously received the HBV vaccine was significantly different between quintiles with the lowest rates in Q1 (18.6\%) and higher rates in Q5 $(40.4 \%)(P<0.05)$. Only $1.1 \%$ injected 3 doses of vaccine during the pregnancy. People with higher income were more likely to be injected with a higher number of doses $(P<0.05)$. Among all quintiles, $62.3 \%$ of women were willing to pay for the HBV vaccine, with a mean maximum amount of US\$10.30. No significant difference was found between quintile groups regarding WTP and the maximum amount.

The Lorenz curves in Figure 2 show that the distribution of previous HBV vaccination was not equalized (Gini coefficient=0.13) when household income was taken into account. On the other hand, the distribution of WTP for the HBV vaccine was approximately equalized (Gini coefficients=0.02) among the various household income levels.

Figure 3 shows the cumulative percentage of participants willing to pay various amounts for HBV vaccination by household income quintiles. Differences between Q1 and Q5 were significant at US\$9, \$18, and\$36.
Table 3 shows that $37.7 \%$ of women were not willing to pay for the vaccine. The major reason was "not necessary" (45.2\%), following by "no risk of HBV infection" (18.4\%), "others" (17.2\%), and "already injected" (16.5\%). Significant differences between people who were and were not willing to pay for the vaccine were found in education levels; awareness of HBV vaccine; and using school, radio/ loudspeaker, Internet, and friends/relatives as sources of information $(P<.05)$.

Table 4 reveals that income quintile groups (except Q2 for WTP) were not independent factors associated with previous HBV vaccination, WTP, and the amount willing to pay for HBV vaccine after adjusting for other confounders. Women with university degrees, without spouse/partner, who received vaccine information from newspapers/ magazines, and who had heard about HBV vaccination were more likely to have been previously vaccinated against HBV. The source of vaccination information was found to be associated with WTP for the HBV vaccine. Education, marital status, and source of information were associated with the maximum amount participants were willing to pay.

\section{DISCUSSION}

Overall, we found that $62.3 \%$ of all study participants were willing to pay for the HBV vaccine, a higher rate than previous studies among Malaysians 
TABLE 2. Hepatitis B Vaccination Awareness, Uptake, and Willingness to Pay Among Participants in Study of Effects of Household Income on Willingness to Pay for the Vaccine, Hanoi, Vietnam, (n=695)

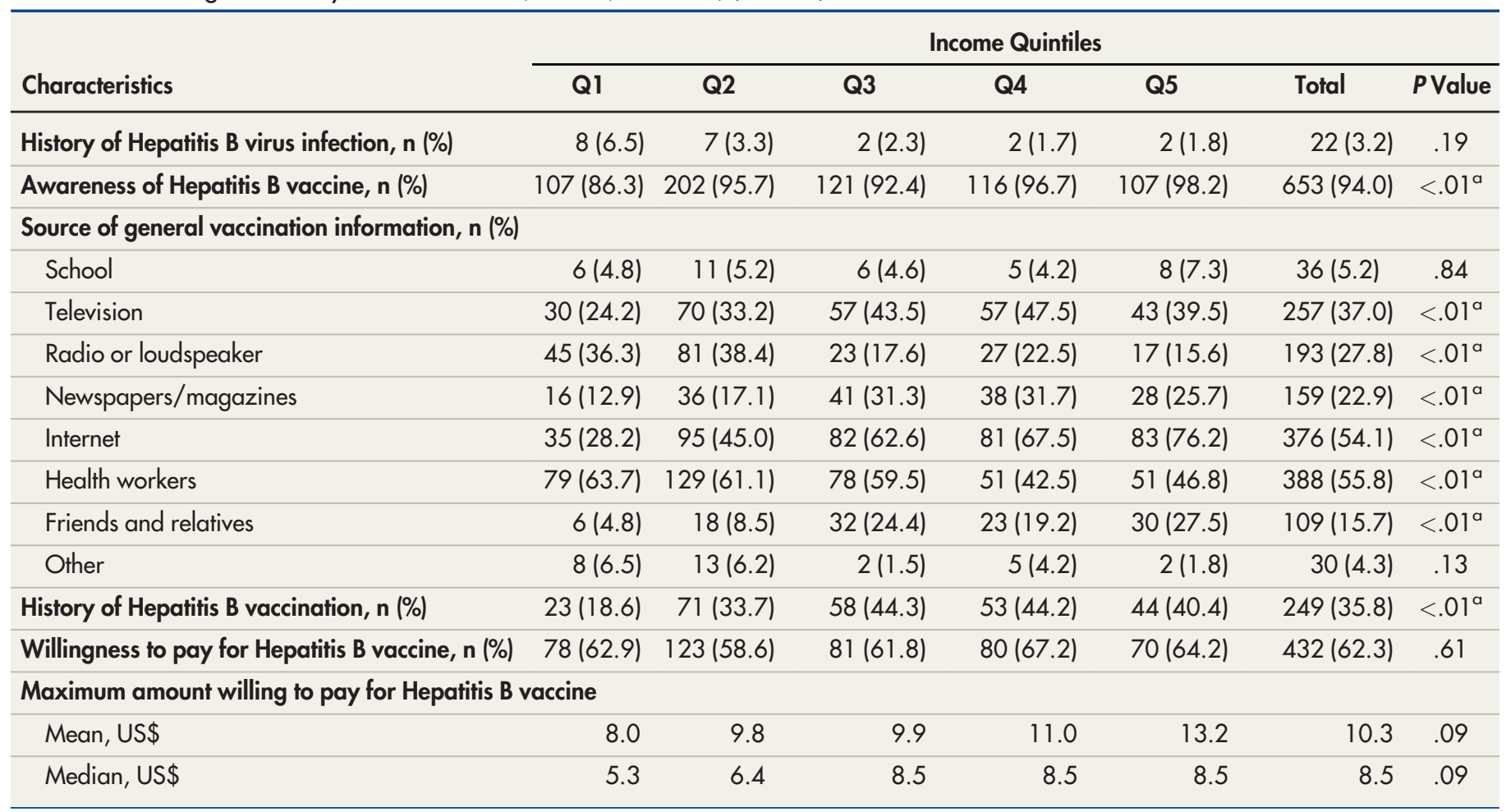

a Significant at $P<.05$.

FIGURE 2. (a) Lorenz Curve Showing History of Hepatitis B Vaccination Among Women of Reproductive Age, Hanoi, Vietnam, by Monthly Household Income; (b) Lorenz Curve Showing Willingness to Pay for One Dose of Hepatitis B Vaccine Among Women of Reproductive Age, Hanoi, Vietnam, by Monthly Household Income
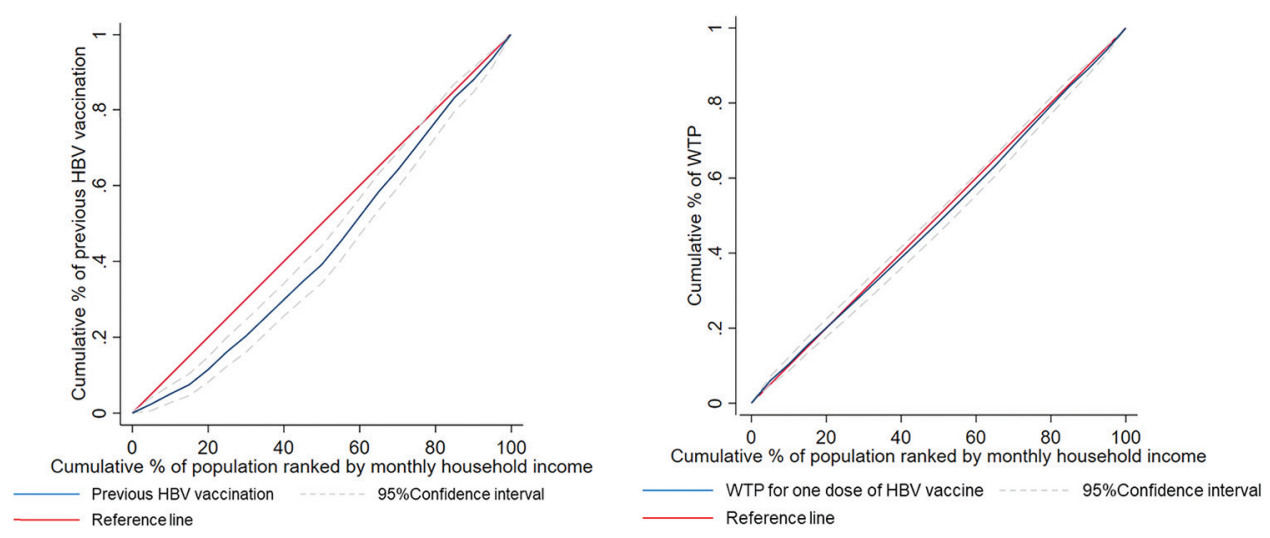

Abbreviations: HBV, hepatitis B virus; WTP, willingness to pay. 
FIGURE 3. Cumulative Percentage of Women Willing to Pay Various Amounts for Hepatitis B Vaccine, Hanoi, Vietnam, by Household Income Quintile

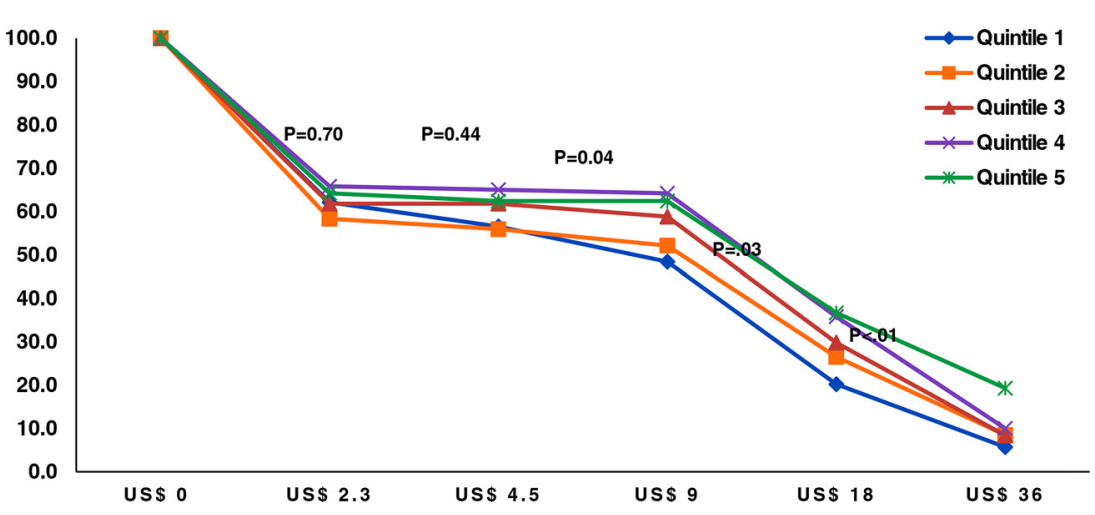

(37.5\%) and Chinese Americans in New York City $(53.2 \%) .^{18,19}$ Women across the income spectrum were willing to pay for HBV vaccination at similar rates. Among those willing to pay, the mean maximum was US\$10.30, over twice the amount found by a similar study in 2016 (108,600 VND, US

From a costeffectiveness standpoint, the benefits of vaccinating WRA extends beyond the individual vaccinated to her future children as well.

\section{These data} demonstrate that the current market price of the HBV vaccine is inaccessible to the majority of lowincome women, suggesting the need to subsidize HBV vaccinations for women from low-income households. \$4.73). ${ }^{13}$ When participants were asked how much they were willing to pay, differences between income levels emerged for maximum prices greater than US $\$ 4.50$. We found that $50 \%$ of women from Q4 and Q5 were willing to pay a maximum price between US\$9-US\$18, whereas $50 \%$ of women from Q1 were willing to pay less than US\$9. When the WTP percentage is increased to $60 \%$, women from Q1 were willing to pay between US\$2.30-US\$4.50 and Q5 between US\$9-US\$18.

These data demonstrate that the current market price of the HBV vaccine (approximately US \$9) is inaccessible to the majority of low-income women, suggesting the need to subsidize HBV vaccinations for women from low-income households. Ideally, these subsidizations should be funded through national grants, which is typically more stable than foreign aid-though foreign aid may be considered for short-term assistance. However, due to limitations with both of these funding options, a possible solution could be to create a sliding scale for HBV vaccination based on household income in which high-income women pay an amount greater than the market price to subsidize the cost for low-income women. Given that the average maximum price participants were willing to pay was greater than the current market price, it appears that such a vaccination program among WRA could be financed by the high- income recipients of the vaccine alone. However, further research would be required to evaluate consumer acceptance of this payment scheme and to develop an appropriate sliding scale to maximize vaccine uptake.

Because HBV is primarily transmitted vertically in Vietnam, we believe that increasing vaccination among WRA would work synergistically with current neonatal vaccination efforts to decrease transmission and confer immunity. This effort is especially important for women in rural or mountainous areas, whereas many as half may deliver their neonates at home, ${ }^{20}$ and neonatal vaccination may not be immediately available. With limited resources to dedicate toward a widespread HBV vaccination campaign, the government should prioritize vaccinating WRA given their high risk of disease transmission. From a cost-effectiveness standpoint, the benefits of vaccinating WRA extend beyond the individual vaccinated to all of her future children as well.

At the same time, this vaccination strategy should be paired with an education campaign, given that improved knowledge has previously been demonstrated to be associated with higher WTP. ${ }^{21}$ In particular, our data found that women from Q1 had the lowest level of awareness, suggesting that future campaigns should especially focus on lowincome women. Information should be distributed through radio programs and over loudspeakers, which are more readily available to all women. Indeed, we found that mediums requiring greater financial investment, such as television, magazines/ newspapers, and the Internet, were significantly less used among women in the lowest-income quintiles. Moreover, some studies have found a higher 
TABLE 3. Characteristics of Participants Who Were and Were Not Willing to Pay for Hepatitis B Vaccines and Reasons for Not Willing to Pay

\begin{tabular}{|c|c|c|c|}
\hline Characteristics & Not Willing to Pay & Willing to Pay & PValue \\
\hline Total, n (\%) & $261(37.7)$ & $432(62.3)$ & \\
\hline Age, mean (SD), years & $27.2(6.8)$ & $27.0(5.0)$ & .92 \\
\hline Household monthly income, mean (SD), US\$ & $642.8(550.9)$ & $676.2(548.6)$ & .36 \\
\hline Married, $\mathbf{n}(\%)$ & $258(98.9)$ & $419(97.9)$ & .35 \\
\hline Living in rural area, $\mathrm{n}(\%)$ & $122(48.8)$ & $215(50.1)$ & .74 \\
\hline Having any children, $\mathbf{n}(\%)$ & $242(92.7)$ & $399(92.4)$ & .86 \\
\hline \multicolumn{4}{|l|}{ Education, $n(\%)$} \\
\hline$\leq$ Secondary & $45(17.2)$ & $49(11.3)$ & .03 \\
\hline High & $72(27.6)$ & $143(33.1)$ & \\
\hline Vocational training & $43(16.5)$ & $94(21.8)$ & \\
\hline University & $101(38.7)$ & $146(33.8)$ & \\
\hline History of hepatitis B vaccine, $n$ (\%) & $10(3.9)$ & $12(2.8)$ & .44 \\
\hline Awareness of hepatitis B vaccine, $n$ (\%) & $239(91.6)$ & $413(95.6)$ & .03 \\
\hline \multicolumn{4}{|l|}{ Source of general vaccination information, $\mathbf{n}(\%)$} \\
\hline School & $20(7.7)$ & $16(3.7)$ & .02 \\
\hline Television & $86(33.0)$ & $171(39.6)$ & .08 \\
\hline Radio or loudspeaker & $61(23.4)$ & $132(30.6)$ & .04 \\
\hline Newspapers/magazines & $57(21.8)$ & $102(23.6)$ & .59 \\
\hline Internet & $125(47.9)$ & $251(58.1)$ & $<.01$ \\
\hline Health workers & $134(51.3)$ & $253(58.6)$ & .06 \\
\hline Friends and relatives & $31(11.9)$ & $78(18.1)$ & .03 \\
\hline Other & $9(3.5)$ & $20(4.6)$ & .45 \\
\hline History of hepatitis B vaccination, $n(\%)$ & $91(34.9)$ & $158(36.6)$ & .65 \\
\hline \multicolumn{4}{|l|}{ Reasons for not being willing to pay } \\
\hline Not necessary & $118(45.2)$ & & \\
\hline Unaffordable & $7(2.7)$ & & \\
\hline No risk of hepatitis B virus infection & $48(18.4)$ & & \\
\hline Already injected & $43(16.5)$ & & \\
\hline Others & 45 (17.2) & & \\
\hline
\end{tabular}

Abbreviation: SD, standard deviation.

WTP for vaccines against chronic disease with high morbidity and mortality, ${ }^{22}$ suggesting that future education campaigns should not only focus on raising awareness of HBV vaccination but also provide further education on HBV's related morbidity and mortality.

The cost of treating HBV and its complications in Vietnam is estimated to total US\$4.4 billion in 2008 alone. ${ }^{23}$ Given that HBV prevalence is projected to increase from 6.4 million cases in 1990 to 8.0 million in $2025,{ }^{24}$ this amount will likely be greater in the coming years. The costeffectiveness of universal newborn HBV vaccination has been well-studied, ${ }^{25}$ and our proposed strategy would operate synergistically to reduce vertical transmission to neonates at a minimal cost to the Vietnamese government. Aside from an initial investment in research, 
TABLE 4. Factors Associated With Willingness to Pay for HBV Vaccine and Maximum Amount

\begin{tabular}{|c|c|c|c|c|c|c|}
\hline \multirow[b]{2}{*}{ Characteristic } & \multicolumn{2}{|c|}{$\begin{array}{l}\text { Previous HBV } \\
\text { vaccination }\end{array}$} & \multicolumn{2}{|c|}{$\begin{array}{l}\text { WTP for HBV } \\
\text { vaccine }\end{array}$} & \multicolumn{2}{|c|}{$\begin{array}{l}\text { Amount of WTP for one dose } \\
\text { of HBV vaccine }\end{array}$} \\
\hline & OR & $95 \% \mathrm{Cl}$ & OR & $95 \% \mathrm{Cl}$ & Coef. & $95 \% \mathrm{Cl}$ \\
\hline \multicolumn{7}{|l|}{ Education } \\
\hline$\leq$ Secondary & ref & & ref & & ref & \\
\hline High & 0.99 & $0.52,1.88$ & 1.55 & $0.89,2.69$ & $6.44^{a}$ & $1.95,10.93$ \\
\hline University & $2.29^{a}$ & $1.16,4.51$ & 0.89 & $0.49,1.62$ & 3.17 & $-1.65,7.99$ \\
\hline \multicolumn{7}{|l|}{ Household monthly income quintiles } \\
\hline Q1 & ref & & ref & & ref & \\
\hline Q2 & 1.73 & $0.97,3.10$ & $0.58^{a}$ & $0.35,0.98$ & -1.14 & $-5.24,2.96$ \\
\hline \multicolumn{7}{|l|}{ Marital status } \\
\hline Having spouse/partner & ref & & ref & & ref & \\
\hline Other & $4.04^{a}$ & $1.06,15.5$ & 4.69 & $0.92,23.89$ & $12.29^{a}$ & $1.76,22.83$ \\
\hline \multicolumn{7}{|l|}{ Living area } \\
\hline Urban area & ref & & & & & \\
\hline Rural area & 0.70 & $0.46,1.08$ & & & & \\
\hline \multicolumn{7}{|l|}{ Source of general vaccination information } \\
\hline School (Yes vs. No-ref) & & & $0.33^{a}$ & $0.16,0.69$ & -5.00 & $-11.03,1.03$ \\
\hline No & ref & & ref & & & \\
\hline Yes & $4.54^{\mathrm{a}}$ & $1.33,15.49$ & 1.65 & $0.79,3.44$ & & \\
\hline
\end{tabular}

Abbreviations: Coeff, coefficient; Cl, confidence interval; HBV, hepatitis B virus, OR, odds ratio; WTP, willingness to pay.

${ }^{a} p<.05$.

implementation, and education, this vaccination program would be financially selfsustaining, a step toward more equitable health outcomes for decades to come.

\section{Limitations}

Limitations of this study include its crosssectional nature, which only allowed for us to test for association without insight into causative relationships-though we were able to correlate some results with a previous study conducted in the same districts in 2016. Another limitation is that this study involves selfreporting, which could predispose participants to recall or social desirability bias. Moreover, while participants do not represent all WRA in Vietnam, we did implement random sampling from both urban and rural environments, ensuring that participants from a variety of backgrounds were included in this survey. 
Author contributions: XTTL, NTTN, HTL, TTD, THN, HLTN led this research, including proposal write up, and designed the instrument XTTL, NTTN, HTL collected and analyzed data. XTTL, NTTN, BXT, CAL, $\mathrm{CSSH}, \mathrm{RCMH}$ discussed data and wrote the manuscript. All authors read and approved the final manuscript.

Competing interests: None declared.

\section{REFERENCES}

1. Hepatitis B. World Health Organization. June 27, 2020. Accessed July 14, 2020. https://www.who.int/news-room/fact-sheets/ detail/hepatitis-b

2. Huy Do S. Epidemiology of Hepatitis $B$ and $C$ virus infections and liver cancer in Vietnam. Euroasian J Hepatogastroenterol. 2015;5 (1):49-51. CrossRef. Medline

3. Nakata $S$, Song $P$, Duc DD, et al. Hepatitis $C$ and $B$ virus infections in populations at low or high risk in $\mathrm{Ho}$ Chi Minh and Hanoi, Vietnam. J Gastroenterol Hepatol. 1994;9(4):416-419. CrossRef. Medline

4. Hipgrave DB, Nguyen TV, Vu MH, et al. Hepatitis B infection in rural Vietnam and the implications for a national program of infant immunization. Am J Trop Med Hyg. 2003;69(3):288-294. CrossRef. Medline

5. Nguyen VTT, McLaws ML, Dore GJ. Highly endemic hepatitis B infection in rural Vietnam. J Gastroenterol Hepatol. 2007;22 (12):2093-2100. CrossRef. Medline

6. Chen WH, Yin CS, Chang YK, Yan JS, Chu ML. Neonatal gastric aspirates as a predictor of perinatal hepatitis $B$ virus infections. Int $J$ Gynaecol Obstet. 1998;60(1):15-21. CrossRef. Medline

7. Cheung KW, Seto MTY, Wong SF. Towards complete eradication of hepatitis $B$ infection from perinatal transmission: review of the mechanisms of in utero infection and the use of antiviral treatment during pregnancy. Eur J Obstet Gynecol Reprod Biol. 2013;169 (1):17-23. CrossRef. Medline

8. Stevens CE, Beasley RP, Tsui J, Lee WC. Vertical transmission of hepatitis B antigen in Taiwan. N Engl J Med. 1975;292(15):771774. CrossRef. Medline

9. Jonas MM. Hepatitis B and pregnancy: an underestimated issue. Liver Int. 2009;29(Suppl 1):133-139. CrossRef. Medline

10. Do SH, Yamada H, Fujimoto $M$, et al. High prevalences of hepatitis $B$ and $C$ virus infections among adults living in Binh Thuan province, Vietnam. Hepatol Res. 2015;45(3):259-268. CrossRef. Medline

11. $\mathrm{Ni} Y H$, Huang $L M, C$ hang $M H$, et al. Two decades of universal hepatitis $B$ vaccination in Taiwan: impact and implication for future strategies. Gastroenterology. 2007;132(4):1287-1293. CrossRef. Medline

12. Anh HNS, Vo HL, Bao LH, Minh HT, Thu HTT, Kien VD. Hepatitis B birth dose vaccination among Vietnamese children: implications for the Expanded Program on Immunization. BioMed Res Int. 2019;2019:3453105. CrossRef. Medline

13. Nguyen ATL, Le XTT, Do TTT, et al. Knowledge, preference, and willingness to pay for hepatitis $B$ vaccination services among woman of reproductive age in Vietnam. Biomed Res Int. 2019:9154918. CrossRef. Medline

14. Sangkomkamhang US, Lumbiganon $P$, Laopaiboon M. Hepatitis $B$ vaccination during pregnancy for preventing infant infection. Cochrane Database Syst Rev. 2014(11). CrossRef. Medline

15. Ladinsky JL, Nguyen HT, Volk ND. Changes in the health care system of Vietnam in response to the emerging market economy. J Public Health Policy. 2000;21(1):82-98. CrossRef. Medline

16. Zhu D, Guo N, Wang J, et al. Socioeconomic inequality in Hepatitis B vaccination of rural adults in China. Hum Vaccin Immunother. 2018;14(2):464-470. CrossRef. Medline

17. Park B, Choi KS, Lee HY, Jun JK, Park EC. Socioeconomic inequalities in completion of hepatitis B vaccine series among Korean women: results from a nationwide interview survey. Vaccine. 2012;30 (40):5844-5848. CrossRef. Medline

18. Rajamoorthy Y, Radam A, Taib NM, et al. Willingness to pay for hepatitis B vaccination in Selangor, Malaysia: a cross-sectional household survey. PLoS One. 2019;14(4):e0215125. CrossRef. Medline

19. Ma G, Shive SE, Toubbeh JI, Tan Y, Wu D. Knowledge, attitudes, and behaviors of Chinese hepatitis B screening and vaccination. Am J Health Behav. 2008;32(2):178-187. CrossRef. Medline

20. Goland E, Hoa DT, Målqvist M. Inequity in maternal health care utilization in Vietnam. Int J Equity Health. 2012;1 1(1):24. CrossRef. Medline

21. Hou Z, Chang J, Yue D, Fang H, Meng Q, Zhang Y. Determinants of willingness to pay for self-paid vaccines in China. Vaccine. 2014;32 (35):4471-4477. CrossRef. Medline

22. Kim S-Y, Sagiraju HKR, Russell LB, Sinha A. Willingness-to-pay for vaccines in low-and middle-income countries: a systematic review. Ann Vaccines Immunization. 2014;1(1):1001. Accessed July 14, 2021. https://www.jscimedcentral.com/Vaccines/vaccines-1-1001.pdf

23. Tu HAT, Woerdenbag HJ, Riewpaiboon A, et al. Cost of illness of chronic hepatitis B infection in Vietnam. Value Health Reg Issues. 2012;1(1):23-28. CrossRef. Medline

24. Nguyen VTT, Law MG, Dore GJ. An enormous hepatitis B virusrelated liver disease burden projected in Vietnam by 2025. Liver Int. 2008;28(4):525-531. CrossRef. Medline

25. Tu HAT, de Vries R, Woerdenbag HJ, et al. Cost-effectiveness analysis of Hepatitis B immunization in Vietnam: application of cost-effectiveness affordability curves in health care decision making. Value Health Reg Issues. 2012;1(1):7-14. CrossRef. Medline

\section{Peer Reviewed}

Received: August 12, 2020; Accepted: July 1, 2021.

Cite this article as: Le XTT, Nguyen NTT, Le HT, et al. Income inequalities in hepatitis B vaccination and willingness to pay among women of reproductive age in Hanoi, Vietnam. Glob Health Sci Pract. 2021;9(3):523-531. https://doi.org/10.9745/GHSP-D-20-00480

(C) Le et al. This is an open-access article distributed under the terms of the Creative Commons Attribution 4.0 International License (CC BY 4.0), which permits unrestricted use, distribution, and reproduction in any medium, provided the original author and source are properly cited. To view a copy of the license, visit https://creativecommons.org/licenses/by/4.0/. When linking to this article, please use the following permanent link: https://doi. org/10.9745/GHSP-D-20-00480 